\title{
Optimizing Slag Content to Control Ds-Type Inclusions in 10B21 Cold Heading Steel
}

\author{
Zhaoqi Song ${ }^{1}$, Wei Liu ${ }^{1} * \mathbb{C}$, Yuhang Liu ${ }^{1}$, Yongfeng Chen ${ }^{2}$, Xiaotan Zuo ${ }^{2}$, Shufeng Yang ${ }^{1, *}$ and Jingshe $\mathrm{Li}^{1}$ \\ 1 School of Metallurgical and Ecological Engineering, University of Science and Technology Beijing, \\ Beijing 100083, China; songzhaoqi97@163.com (Z.S.); eagle0825@163.com (Y.L.); lijingshe@ustb.edu.cn (J.L.) \\ 2 Wuhu Xinxing Casting Pipe Co., Ltd., Wuhu 241000, China; y-f-chen@163.com (Y.C.); \\ zuoxiaotan345@163.com (X.Z.) \\ * Correspondence: liuwei@ustb.edu.cn (W.L.); yangshufeng@ustb.edu.cn (S.Y.)
}

check for updates

Citation: Song, Z.; Liu, W.; Liu, Y.; Chen, Y.; Zuo, X.; Yang, S.; Li, J. Optimizing Slag Content to Control Ds-Type Inclusions in 10B21 Cold Heading Steel. Minerals 2021, 11, 1016. https://doi.org/10.3390/min11091016

Academic Editors: Basak Anameric and Timothy C. Eisele

Received: 20 July 2021

Accepted: 16 September 2021

Published: 18 September 2021

Publisher's Note: MDPI stays neutral with regard to jurisdictional claims in published maps and institutional affiliations.

Copyright: (c) 2021 by the authors. Licensee MDPI, Basel, Switzerland. This article is an open access article distributed under the terms and conditions of the Creative Commons Attribution (CC BY) license (https:/ / creativecommons.org/licenses/by/ $4.0 /)$.
Abstract: Ds-type inclusions during production are an important factor affecting the performance and quality of manufactured 10B21 steel. To minimize Ds-type inclusions in steel and improve the production qualification rate of steelmaking plants, a refining slag system optimization scheme was proposed based on the analysis of current inclusion evolution during the steelmaking process, and industrial tests were conducted to verify improvements resulting from application of the proposed scheme. The results showed that the composition of Ds inclusions in 10B21 steel are mainly CaO$\mathrm{Al}_{2} \mathrm{O}_{3}-\mathrm{MgO}-\mathrm{CaS}-\mathrm{TiN}$, which exists in the form of calcium-magnesium aluminate coated with titanium nitride and calcium sulfide. The main reason for the formation of Ds inclusions is the poor fluidity of the refining slag and its low capability to absorb inclusions. The poor coverage of the refining slag on the molten steel during refining can easily cause secondary oxidation of the molten steel. Thus, the formation and growth of Ds-type inclusions are aggravated after the calcium feeding line and soft blowing operation. Here, we propose to minimize Ds inclusions using our optimized refined slag system. The mass percentage of the optimized slag system is $\mathrm{CaO}: 55-60 \%, \mathrm{Al}_{2} \mathrm{O}_{3}$ : $20-35 \%, \mathrm{SiO}_{2}: 3-7 \%, \mathrm{MgO}: 4-8 \%,(\mathrm{MnO}+\mathrm{FeO})<1 \%$, and the basicity is controlled within the range of 7-11. We observed that our optimized refining slag system has a significantly improved ability to remove inclusions, particularly Ds inclusions, which improves the qualification rate of $10 \mathrm{~B} 21$ steel.

Keywords: 10B21 steel; slag system optimization; Ds inclusions; cleanliness; industrial test

\section{Introduction}

10B21 steel can be processed into standard parts by cold heading and is widely used in many industries such as in machinery, automobiles, construction, and electrical appliances [1-3]. Cold heading is an important method for forming standard parts such as fasteners and connectors. Therefore, 10B21 steel is required to meet certain standards for application, for example regarding its strength, plasticity, and toughness. Fasteners and connectors have a special working environment, and their fatigue resistance can be considered as a centralized embodiment of the comprehensive mechanical properties of 10B21 [4-6]. The main factor affecting the fatigue resistance of steel is the nonmetallic inclusions in the steel. Ds inclusions are a typical representative that impacts fatigue resistance. Ds inclusions are a class of inclusions specified in the Chinese national standard as spherical inclusions of a size greater than $13 \mu \mathrm{m}$. The mechanisms by which Ds inclusions cause steel fatigue failure include the formation of cracks, voids, phase transformations, and shape defects. Ds inclusions occur in various forms, and the larger their diameter, the greater their impact on steel performance and, hence, the shorter the service life of the steel. Therefore, in production practice, the rating result of Ds inclusions is an important criterion for judging whether 10B21 steel qualifies [7,8]. Wu et al. studied the formation of Ds inclusions in bearing steel during the refining process, and their evolution can be summarized as $\mathrm{Al}_{2} \mathrm{O}_{3} \rightarrow \mathrm{MgO}-\mathrm{Al}_{2} \mathrm{O}_{3} \rightarrow \mathrm{CaO}-\mathrm{MgO}-\mathrm{Al}_{2} \mathrm{O}_{3} \rightarrow$ surrounded by $\mathrm{CaO}-\mathrm{Al}_{2} \mathrm{O}_{3}$ 
$\left(\mathrm{SiO}_{2}\right)$ covered by CaS [9]. The key to solving the problem of Ds inclusions is to control the nucleation and aggregation of Ds inclusions during the refining stage.

To control Ds inclusions, we must start with the factors that affect the occurrence of nonmetallic inclusions in steel. Numerous studies show that refining slag is an important factor influencing nonmetallic inclusion formation in steel. Different refining slag systems can be used to control the morphology, size, and composition of nonmetallic inclusions in steel [10-15]. Sui Yafei et al. changed the viscosity of the refined slag by changing the content of $\mathrm{Al}_{2} \mathrm{O}_{3}$ and $\mathrm{CaF}$ in the slag and used the steel slag balance to control the nonmetallic inclusions in the steel, thereby improving the quality of the steel. Through laboratory experiments [16], Zhao et al. used the total oxygen content to control the size of inclusions in different refining slag series steels, and their formation could even be completely avoided using this rational approach [17].

In this paper, we sought to control the problem of excessive Ds inclusions in 10B21 steel produced by a specific enterprise, by first analyzing the entire process. From this analysis, it was determined that the formation of Ds inclusions were concentrated in the LF refining step, so a comprehensive analysis of the refining slag system of Ds inclusions was conducted and, based on this, an optimization plan for the refining slag system was then proposed. This plan was subject to industrial testing, and the resulting $10 \mathrm{~B} 21$ rolling material was rated for inclusions, and the results of the inclusion classification are compared to those before optimization and analyzed.

\section{Production Status and Optimization Basis}

\subsection{Production Process}

The target composition of 10B21 steel is shown in Table 1. The production of 10B21 cold heading steel by the selected enterprise uses the process flow of 120t BOF (Basic Oxygen Furnace) $\rightarrow$ LF (Ladle Furnace) $\rightarrow$ CC (Continuous Steel Casting). The BOF operation includes control of molten iron composition, control of steel discharge temperature, deoxidation alloying, slag blocking, and steel discharge. The refining operation includes argon blowing and stirring, slag adjusting operation, deoxidizing operation, composition adjustment, calcium treatment, and soft blowing operation. Within this process, the deoxidizer is aluminum block and aluminum wire, the alloying raw materials are high-carbon ferromanganese and high-carbon ferrochrome, and the calcium treatment raw material is pure calcium wire. The specific process operations are as follows.

Table 1. 10B21 target composition requirements (wt\%).

\begin{tabular}{cccccccccc}
\hline Element & C & Si & Mn & P & S & B & Ti & Cr & Alt \\
\hline Mass percentage (\%) & 0.2 & $\leq 0.06$ & 0.9 & $\leq 0.015$ & $\leq 0.01$ & 0.002 & 0.04 & 0.15 & 0.02 \\
\hline
\end{tabular}

The BOF operation and requirements are:

(1) The composition of molten iron is $\leq 0.70 \% \mathrm{Si}, \leq 0.11 \% \mathrm{P}, \leq 150 \mathrm{~mm}$ thick slag layer;

(2) The final component of the converter is $\sim 0.05-0.09 \% \mathrm{C}, \leq 0.012 \% \mathrm{P}$;

(3) Steel tapping temperature before refining should be $\geq 1550{ }^{\circ} \mathrm{C}$;

(4) Alloying-addition of $11 \mathrm{~kg} / \mathrm{t}$ high-carbon ferromanganese to the ladle during tapping; $1.5 \mathrm{~kg} / \mathrm{t}$ high-carbon ferrochrome to ensure that the composition of tapping to LF is within range of $0.12-0.16 \% \mathrm{C}, 0.75-0.85 \% \mathrm{Mn}, 0.10-0.15 \% \mathrm{Cr}, \leq 0.015 \% \mathrm{P}$;

(5) Deoxidizer-40 kg aluminum block per furnace for tapping steel, $400-550 \mathrm{~m}$ aluminum wire per furnace, and after the furnace, ensuring that the $\mathrm{Al}$ content of the refined molten steel is $0.050-0.070 \%$;

(6) Tapping slag material—lime $500 \mathrm{~kg} /$ furnace, slagging agent $100 \mathrm{~kg} /$ furnace.

The refining operations and requirements are as follows:

(1) Argon blowing and stirring-LF refining time $\geq 40 \mathrm{~min}$;

(2) Slag adjustment operation - addition of 400-600 kg lime to ensure good fluidity of the refined slag and to control the basicity of the final slag $\mathrm{R} \geq 3.0$; 
(3) Deoxidation operation-diffusion deoxidation is carried out throughout the refining process, and the final slag $(\% \mathrm{FeO})+(\% \mathrm{MnO})$ is controlled to be less than $1.2 \%$;

(4) Composition adjustment-improving the endpoint composition hit rate and adding ferro-titanium after refining the white slag. The composition adjustment prohibits the use of silicon-containing materials;

(5) Wire feeding treatment-feeding pure calcium wire before soft blowing to ensure the $\mathrm{Ca} / \mathrm{Al}$ ratio of $0.08-0.15$.

The cross-sectional size of the small billet was $180 \mathrm{~mm} \times 180 \mathrm{~mm}$, and the casting speed was $1.30 \mathrm{~m} / \mathrm{min}$. The performance and quality of the steel grade produced by this enterprise was low, and the initial inspection qualification rate was only $88.18 \%$. In order to investigate the reasons affecting the quality of 10B21 steel grade and improve the production qualification rate of this steel grade, the change trend in steel and slag samples during the smelting process was analyzed.

\subsection{Sample Preparation and Testing}

10B21 was sampled throughout the entire production process, and steel samples were taken at the refining station before and after the converter, at the LF station, before and after the calcium treatment, before the soft blowing station, and in the middle and late stages of the tundish pouring. In terms of the refined slag sample, the microscopic morphology and composition of the inclusions in the taken steel product were detected using scanning electron microscopy combined with image analysis, and the change in oxygen and nitrogen content in each process was determined by oxygen and nitrogen analysis. In addition, a full section cast billet sample with a length of $200 \mathrm{~mm}$ was taken from the continuous cast billet as a big sample for electrolytic analysis. Electrical wire cutting was used to process the $\Phi 5 \times 100 \mathrm{~mm}$ bar samples for measuring total oxygen and nitrogen content, the $15 \times 15 \times 15 \mathrm{~mm}^{3}$ metallographic sample, and the $50 \times 50 \times 150 \mathrm{~mm}^{3}$ big sample from the hanging bucket sample and the cast billet sample. The bar samples for measuring total oxygen and nitrogen content should be sealed after polishing. Before testing, we ensured that there was no iron oxide scale on the surface. The metallographic sample should ensure that there is no residue of polishing paste after polishing. The surface of the big sample remained smooth after polishing. After grinding the taken slag sample, it was filtered with a sieve with a mesh diameter of $74 \mu \mathrm{m}$, and the filtered slag powder was put into an oven and dried at $110{ }^{\circ} \mathrm{C}$ for $5 \mathrm{~h}$. The analytical instruments that were used are shown in Table 2. After detecting the composition of the slag, we used the Phase Diagram module of the thermodynamic software FactSage 7.1 to calculate the phase diagram, and the FToxid (2017) database was used.

Table 2. Sample analysis instruments.

\begin{tabular}{ccc}
\hline Sample & Analytical Instruments & Equipment Information \\
\hline Metallographic & Phenom ParticleX Electronic Scanning Electron & Netherlands Phenom \\
Slag & Microscope & Netherlands PANalytical B.V. \\
Oxygen and nitrogen rod & American LECO Nitrogen and Oxygen Analyzer & American LECO \\
Big sample electrolysis & Phenom ProX scanning electron microscope & Netherlands Phenom \\
\hline
\end{tabular}

\subsection{Evolution of Inclusions during the Steelmaking Process}

Figure 1 shows the changing trend of the total oxygen content and the number density of inclusions in the steel during the refining process, where LF1 represents the refining inlet station, LF2 represents the refining before the calcium feeding line, LF3 represents the refining after the calcium feeding line, and LF4 represents the refining after soft blowing out of the station. The change trend in total oxygen content and the number density of inclusions was similar. The total oxygen content and number density of inclusions in the steel were reduced due to the operation of refining slag adjustment and deoxidation. Due 
to the operation of feeding the calcium wire, the calcium wire underwent a strong oxidation reaction with the oxygen in the slag when passing through the slag layer, generating a large number of calcium oxides in the molten steel, resulting in an increase in both total oxygen content and the number density of inclusions in the steel. Theoretically, during the period from LF3 to LF4, since the bottom blowing argon gas strengthened the stirring of the molten steel, it should promote the passing of inclusions through the steel slag interface into the slag, and the level of inclusions should be reduced. However, as shown in Figure 1, the oxygen content and the number density of inclusions did not change significantly, and the reason for this may have been the problem of the refining slag system.

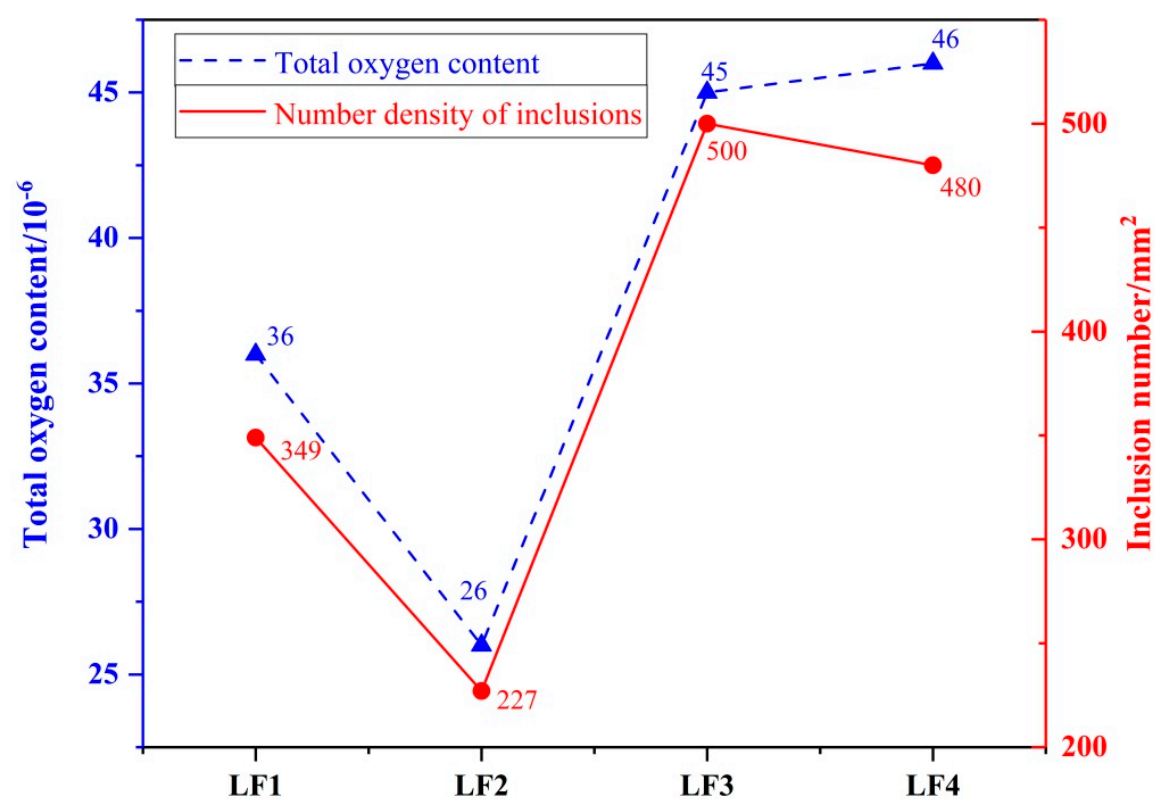

Figure 1. Graph showing trend in total oxygen content and the number density of inclusions.

Figure 2 shows the relationship of the inclusion size and the percentage of the inclusion area during the refining process. Because the calcium feeding wire had the effect of modifying the inclusions, the melting point of the inclusions was reduced and they readily polymerized and grew, resulting in an increase in the size of the inclusions. The soft blowing intensified the stirring of the molten steel, increased the probability of the inclusions colliding and growing, and caused the size of the inclusions to significantly increase. From the error bar of the change in inclusion size, it can be seen that the size of the inclusions fluctuated slightly at the beginning of refining and soft blowing caused the size of the inclusions to fluctuate. Combined with the trend graph of the area proportion of inclusions, it can be seen that as the size of the inclusions increased, the proportion of their area also increased, which demonstrates that new inclusions were generated. Considering the poor coverage of the refining slag system to the molten steel, this led to the secondary oxidation of the molten steel.

Figure 3 shows the typical inclusion morphology and energy spectrum during the refining process. The inclusions in the refining station were mainly $\mathrm{Al}_{2} \mathrm{O}_{3}, \mathrm{MnS}$, and $\mathrm{Al}_{2} \mathrm{O}_{3}-\mathrm{MnS}$ formed due to the deoxidation operation. Before feeding the calcium wire, the addition of the titanium-iron alloy inhibited the formation of boron nitride, which easily causes cracking, but TiN inclusions appeared in the molten steel. The feeding of calcium wire lowered the melting point of inclusions, had a significant effect on the modification of inclusions, and also provided the conditions for the formation of Ds inclusions. Ds inclusions were generated during the refining process, and their composition was mainly $\mathrm{CaO}-\mathrm{Al}_{2} \mathrm{O}_{3}-\mathrm{MgO}-\mathrm{CaS}-\mathrm{TiN}$, which existed in the form of calcium-magnesium aluminate coated with titanium nitride and calcium sulfide. 


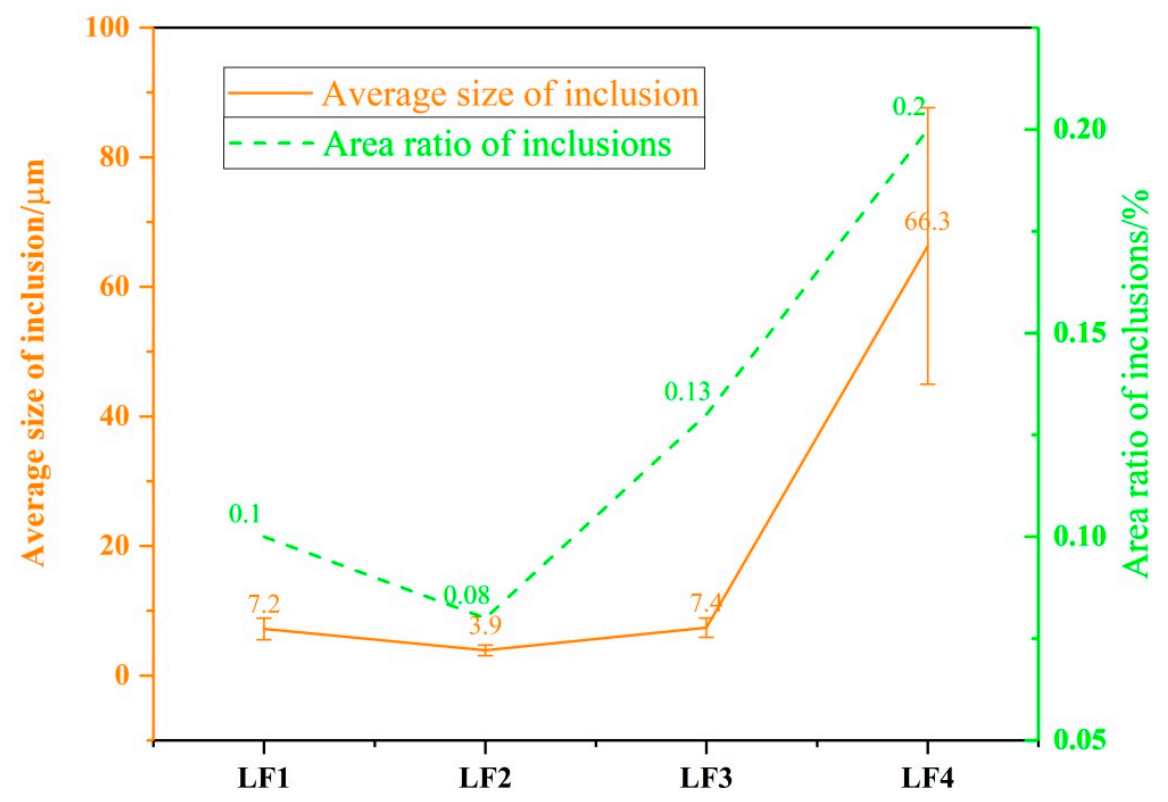

Figure 2. Graph showing trends in the changing inclusion size and the proportion of the inclusion area.

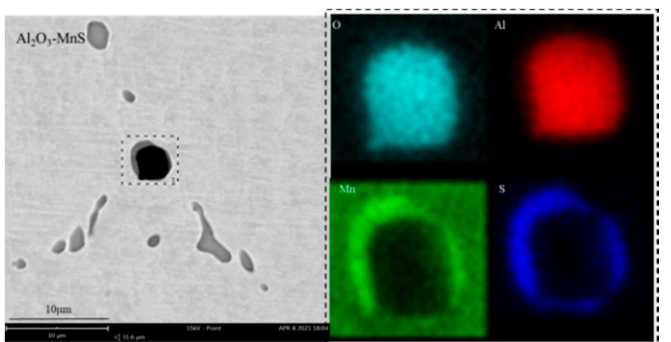

(a)

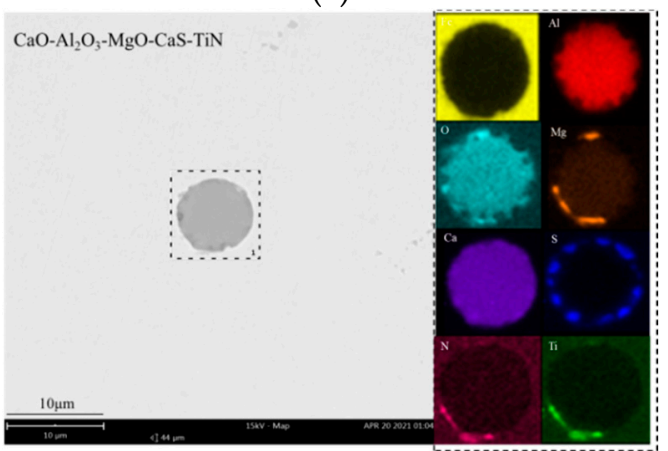

(c)

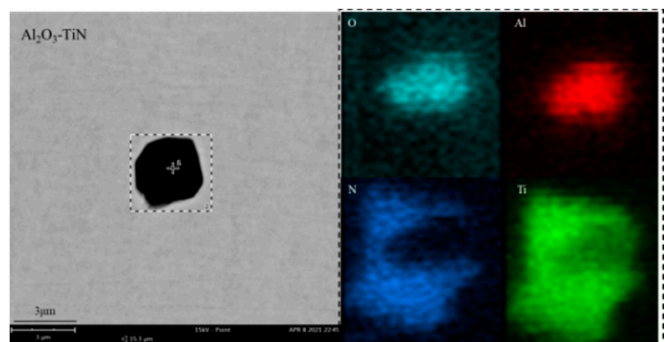

(b)

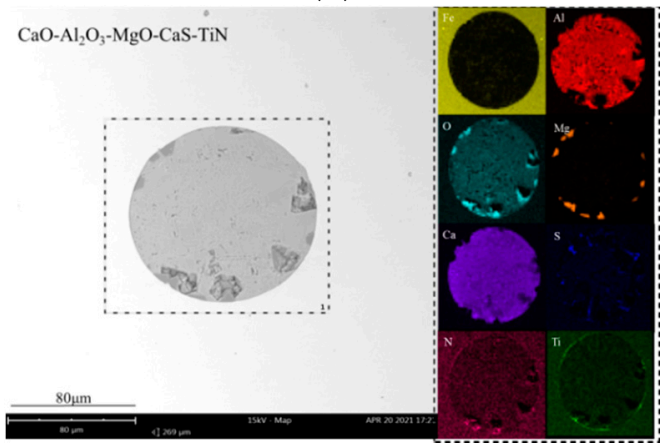

(d)

Figure 3. SEM surface morphology image with EDS elemental mapping analysis: (a) LF1; (b) LF2; (c) LF3; (d) LF4.

The big sample electrolysis method is one of the main methods for testing inclusions in steel. In the specially designed electrolytic lees, the specimen was used as the anode and the metal mesh as the cathode, and the specimen was electrolyzed in a solution prepared by compounds such as $\mathrm{FeSO}_{4}, \mathrm{FeCl}_{2}$, and $\mathrm{ZnCl}_{2}$. Under the action of the electric field, iron is deposited on the cathode, and the inclusions remain in the form of insoluble residues in the anode sludge because they are nonconductor compounds, and the inclusions can finally be obtained by physical separation. The big sample electrolysis method has certain advantages over other electrolysis methods, such as its applicability to big sample sizes, strong representation of inclusions, complete precipitation of inclusions, and easy identification of the source of inclusions. Figure 4 shows the morphology and energy spectrum of the big sample electrolytic inclusions after 10B21 rolling. Figure $4 \mathrm{a}, \mathrm{b}$ are the morphologies of inclusions observed under a $20 \times$ optical microscope. The size of the 
inclusions in (a) was less than $80 \mu \mathrm{m}$, and the size of the inclusions in (b) fluctuated in the range of $80-140 \mu \mathrm{m}$. Figure $4 \mathrm{c}$, d show the SEM morphology and energy spectra of the inclusions, whose compositions matched the large-sized spherical inclusions observed at the refining position, both as $\mathrm{CaO}-\mathrm{Al}_{2} \mathrm{O}_{3}-\mathrm{MgO}-\mathrm{CaS}-\mathrm{TiN}$ in the form of titanium nitride and calcium sulfide-coated calcium-magnesium aluminates.

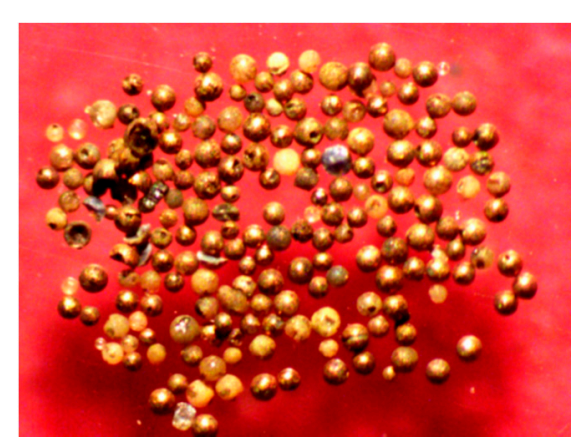

(a)

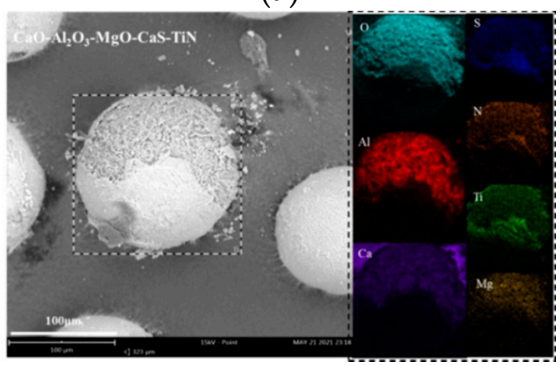

(c)

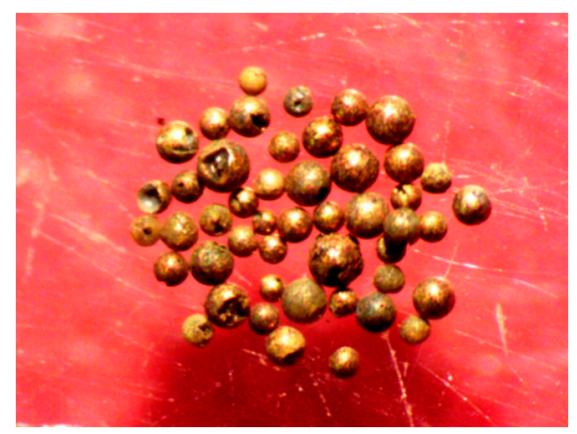

(b)

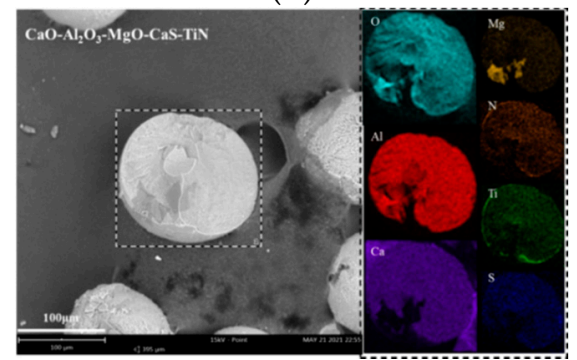

(d)

Figure 4. The surface morphology and EDS analyses acquired from a big simple electrolytic inclusion sample: (a,b) 20× OM image; (c) SEM surface morphology image with EDS elemental mapping analysis; (d) SEM surface morphology image of fracture surface of an inclusion with EDS elemental mapping analysis.

\subsection{Analysis of Slag before Optimization}

As shown in Table 3, the slag samples of LF refining were taken four times during one round of heating and the sampling was repeated for a total of three rounds of heating. In the table, $\mathrm{MI}$ is the Mannesmann index, and the calculation formula is $\mathrm{MI}=(\% \mathrm{CaO}) /\left(\% \mathrm{SiO}_{2}\right)\left(\% \mathrm{Al}_{2} \mathrm{O}_{3}\right)$. The Mannesmann index indicates the fluidity of the slag: the larger the Mannesmann index, the worse the fluidity [18]. It can be seen from Table 3 that the Mannesmann index was positively correlated with the binary basicity. Due to the addition of lime in the slag conditioning operation, the basicity of the final refining slag was significantly increased and unstable, which led to the instability of the Mannesmann index. The fluidity of each furnace slag varied greatly.

Table 4 shows the properties of the original slag system calculated using the thermodynamic calculation software FactSage. Although the slag seemed to be in a molten state during the refining process when observed, the calcium oxide in the slag was not dissolved completely. In addition, through the calculation results and observations of the production site, it was found that the viscosity of the final refining slag was relatively high, which further confirmed the poor fluidity of the slag system. 
Table 3. Changes in the composition of the original refined slag series (wt $\%)$.

\begin{tabular}{cccccccccc}
\hline Heat & Station & $\mathbf{C a O}$ & $\mathbf{S i O}_{2}$ & $\mathbf{A l}_{\mathbf{2}} \mathbf{O}_{\mathbf{3}}$ & $\mathbf{M g O}$ & $\mathbf{M n O}$ & $\mathbf{F e O}$ & $\mathbf{R}$ & $\mathbf{M I}$ \\
\hline \multirow{3}{*}{1} & LF1 & 58.1 & 8.27 & 20.2 & 0 & 6.31 & 2.8 & 7.03 & 0.348 \\
& LF2 & 64.5 & 3.9 & 20.8 & 3.69 & 0.138 & 0.75 & 16.54 & 0.795 \\
& LF3 & 61.7 & 3.15 & 22.4 & 4.12 & 0.128 & 0.86 & 19.59 & 0.874 \\
& LF4 & 61.6 & 3.05 & 22.9 & 4.11 & 0.0878 & 0.36 & 20.20 & 0.882 \\
\hline \multirow{2}{*}{2} & LF1 & 52 & 5.54 & 23.8 & 2.72 & 9.13 & 4.3 & 9.39 & 0.394 \\
& LF2 & 62.1 & 2.23 & 23.3 & 3.65 & 0.19 & 0.82 & 27.85 & 1.195 \\
& LF3 & 60.9 & 1.84 & 23.8 & 4.14 & 0.128 & 0.6 & 33.10 & 1.391 \\
& LF4 & 60.4 & 1.8 & 24 & 4.2 & 0.0774 & 0.5 & 33.56 & 1.398 \\
\hline \multirow{2}{*}{3} & LF1 & 60.2 & 6.45 & 18.1 & 0 & 4.57 & 1.8 & 9.33 & 0.516 \\
& LF2 & 63.5 & 2.99 & 20.3 & 3.43 & 0.147 & 0.954 & 21.24 & 1.046 \\
& LF3 & 64.3 & 3.12 & 20.1 & 3.36 & 0.257 & 0.77 & 20.61 & 1.025 \\
& LF4 & 62 & 3.67 & 20.6 & 3.73 & 0.106 & 0.8 & 16.89 & 0.820 \\
\hline
\end{tabular}

Table 4. The composition ( $\mathrm{w} \mathrm{t} \%$ ) and physical properties of the original refined final slag.

\begin{tabular}{cccccccc}
\hline Heat & $\mathbf{C a O}$ & $\mathbf{S i O}_{\mathbf{2}}$ & $\mathrm{Al}_{\mathbf{2}} \mathbf{O}_{\mathbf{3}}$ & $\mathbf{M g O}$ & Melting Point [K] & Viscosity [Pa·s] & $\begin{array}{c}\text { Solubility of } \\
\text { Calcium Oxide (\%) }\end{array}$ \\
\hline 1 & 61.6 & 3.05 & 22.9 & 4.11 & 1625 & 0.058 & 36.7 \\
2 & 60.4 & 1.8 & 24 & 4.2 & 1612 & 0.059 & 36.2 \\
3 & 62 & 3.67 & 20.6 & 3.73 & 1587 & 0.054 & 35.9 \\
\hline
\end{tabular}

Comprehensive analysis of the various indicators of inclusions in the refining process and the changes in the original slag system revealed that the inclusions that affected the quality of 10B21 steel were mainly large-sized spherical inclusions, namely Ds inclusions. Ds inclusions were generated during the refining process, and the reason for their generation was the ineffective refining slag system. The calcium oxide in the original refining slag was in a supersaturated state, and the slag was too alkaline and the composition of the slag fluctuated greatly, resulting in poor fluidity of the refining slag and unsatisfactory coverage of the molten steel. Part of the molten steel may have been exposed to the air, resulting in secondary oxidation. During the soft blowing process, because the bottom blowing argon aggravated the stirring of the molten steel, the modified low melting point inclusions after calcium treatment quickly aggregated and grew, and had good wettability with the molten steel, so it was difficult for these inclusions to pass through the steel slag interface and enter into the refining slag with poor fluidity. In addition, with the progress of soft blowing, the refining slag with poor fluidity crusted easily, which increased the risk of the secondary oxidation of the molten steel.

To control the Ds inclusions in steel, we must start by optimizing the refining slag system, increasing the fluidity of the refining slag and its ability to protect molten steel, thereby improving the ability of the system to remove inclusions in steel.

\section{Optimization of the Refining Slag System and Industrial Testing}

To avoid fluorine pollution of the environment, the structure of the refining slag was adjusted according to $\mathrm{Gu}$ et al. to obtain a fluorine-free slagging system that met the requirements of smelting, and the effect of removing inclusions in steel was also significantly improved [19]. Zhao $S$ et al. optimized the tapping deoxidation and slag washing system to control the compositions of the molten steel and refining slag, and most of the typical micro inclusions in molten steel were transformed into spherical $\mathrm{MnO}-\mathrm{SiO}_{2}-$ $\mathrm{Al}_{2} \mathrm{O}_{3}$ and $\mathrm{CaO}-\mathrm{MnO}-\mathrm{SiO}_{2}-\mathrm{Al}_{2} \mathrm{O}_{3}$ systems of less than $30 \mu \mathrm{m}$. This not only improved the cleanliness of the molten steel, but also greatly reduced the production cost. When tundish casting is stable, calcium treatment can essentially be eliminated [20]. Ge et al. attempted to solve the problem of cracks and pores in 33MnCrTiB steel and, in their analysis, found that it was the large-sized inclusions that affected the quality of the steel that came from 
refining slag. By optimizing the refining slag and preventing secondary oxidation, the number of macroscopic inclusions in the steel was effectively reduced, and the steel quality problems caused by inclusions were improved [13].

Based on the above analysis, the quality problems of 10B21 steel originated from Ds inclusions, and the reason for the formation of Ds inclusions was an inappropriate refining slag system. Controlling the generation of Ds inclusions or removing Ds inclusions within a limited time has always been the focus of metallurgist researchers. Optimization of the refining slag system is an important way to solve this problem. The influence of the refining slag system on inclusions is apparent, and Ds inclusions, and their removal, are unlikely to be an exception.

\subsection{Refining Slag Content Optimization}

In order to determine the composition control range of the optimized refined slag system, the thermodynamic calculation software FactSage was used to calculate parameters related to the liquid phase region of the slag system. Due to the deoxidation operation during the refining process, both manganese oxide and ferrous oxide were at a low level, so in the process of optimizing the slag system, the proportion of the two was ensured to be less than $1 \%$, and the other main slag system components were normalized. Figure 5 shows the $\mathrm{CaO}-\mathrm{Al}_{2} \mathrm{O}_{3}-\mathrm{SiO}_{2}$ ternary phase diagram of the change in the liquid phase region of the refined slag system with different proportions of magnesium oxide in the slag at the steelmaking temperature. The red dots in the figure represent the average composition of the original slag system. The refined slag system was in the nonliquid phase zone, which further confirmed the poor fluidity of the original slag system. This was also an important factor affecting the absorption of Ds inclusions through the steel slag interface by the refined slag. From the analysis of Figure 5, it can be seen that the higher the proportion of magnesium oxide in the refining slag system, the smaller the liquid phase zone. Therefore, the magnesium oxide in the refining slag system should be controlled as much as possible. In order to improve the fluidity of the slag system, it was necessary to increase the solubility of calcium oxide. The arrow in Figure 5 shows the optimization direction of the refining slag, namely by reducing the content of calcium oxide and increasing the content of aluminum oxide, but this may cause the problem of nozzle clogging. Nozzle clogging is a problem that has persistently plagued many enterprises and scientific researchers. High melting point inclusions are the main reason for nozzle clogging. For aluminum deoxidized steel, the high melting point magnesium aluminum spinel is the culprit for nozzle blockage. In order to reduce the melting point of inclusions in steel, increasing the content of calcium in steel is the most effective method. There are two main ways to increase the calcium element in molten steel. One is through the equilibrium reaction of the steel slag interface, and the other is the feeding of calcium wires during the refining process. Therefore, while increasing the solubility of calcium oxide, it is also necessary to ensure the necessary calcium content for inclusions modification and to ensure a suitable basicity. Regarding 10B21 aluminum deoxidized steel used in the production of fasteners, relatively superior mechanical properties are required, and the silicon content is an important factor that adversely affects the mechanical properties; therefore, the silicon content should be kept at a low level. 


\section{$\mathrm{CaO}-\mathrm{SiO}_{2}-\mathrm{Al}_{2} \mathrm{O}_{3}-\mathrm{MgO}$ \\ $\mathrm{MgO} /\left(\mathrm{CaO}+\mathrm{SiO}_{2}+\mathrm{Al}_{2} \mathrm{O}_{3}+\mathrm{MgO}\right)(\mathrm{g} / \mathrm{g})=0.04 \sim 0.1,1600^{\circ} \mathrm{C}, 1 \mathrm{~atm} \quad$ Fact Sage $\mathrm{e}^{\mathrm{m}}$}

$\mathrm{CaO}$

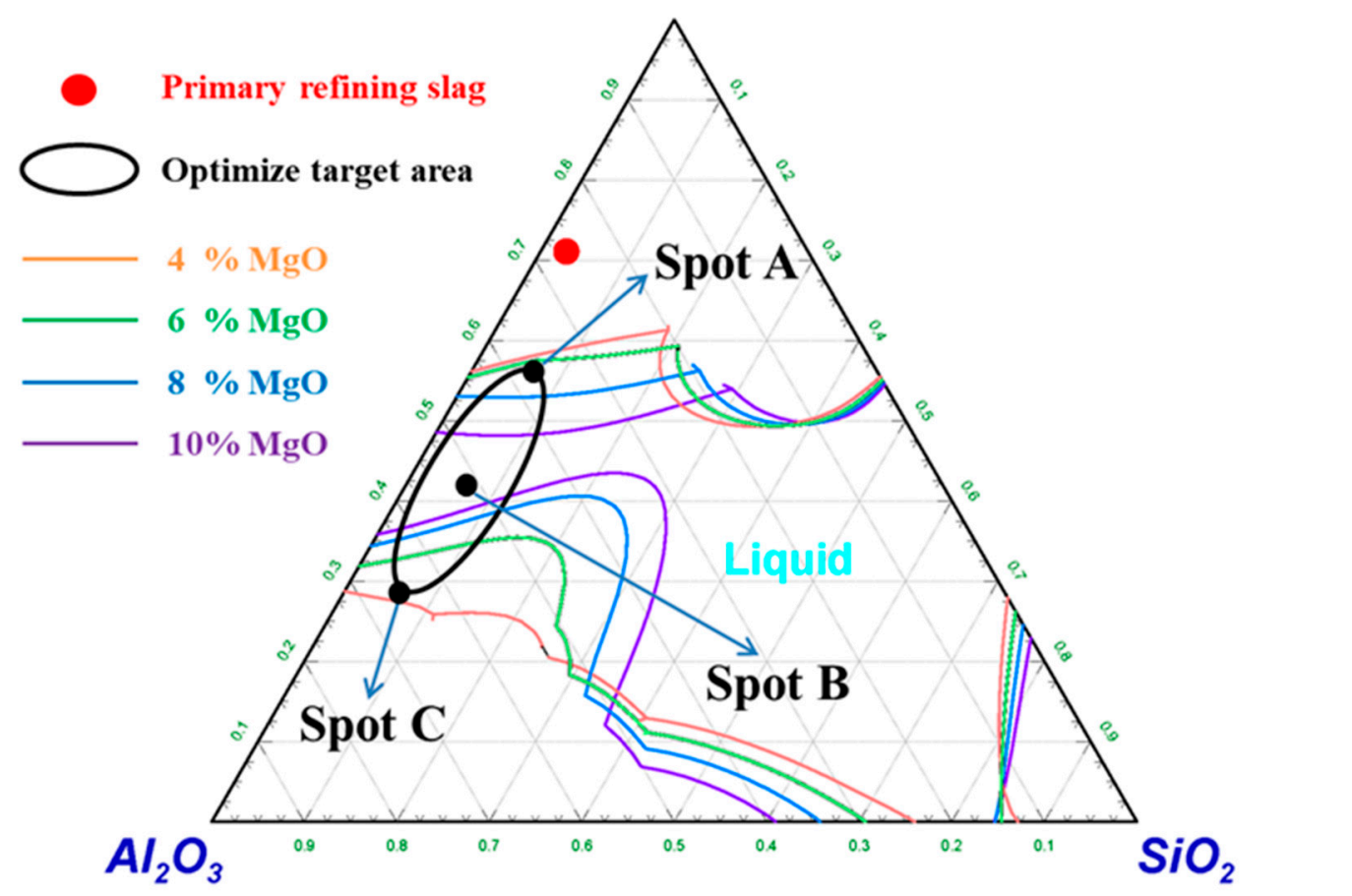

Figure 5. $\mathrm{CaO}-\mathrm{Al}_{2} \mathrm{O}_{3}-\mathrm{SiO}_{2}$ ternary phase diagram.

Three aspects should be paid attention to when optimizing the refining slag. The first is to adjust the refining slag system to be in the liquid phase region of the ternary phase diagram, and the second is to increase the solubility of calcium oxide in the refining slag, reduce the content of calcium oxide, and ensure the necessary basicity. The third is to ensure that the silicon content is at a low level. Therefore, the optimized direction of the slag system was determined in the area shown by the ellipse in Figure 5.

Due to the largeness of the ellipse area in Figure 5, in order to explore the optimal refining slag system and ensure the stability of the refining slag system, it was necessary to reduce the optimization area of the refining slag. By reducing the calcium oxide, the solubility of calcium oxide could be improved, and the basicity of the slag system could be maximized to obtain the best refined slag system. FactSage was used to calculate the solubility and basicity of calcium oxide at three typical points in the ellipse, and the calculation results are shown in Table 5. It can be seen from Table 5 that the calcium oxide dissolution in the slag system could be achieved in the area where the three component points are located in the figure. Among them, point $A$ has the highest basicity and point $C$ has the lowest basicity.

Table 5. Optimized slag composition (wt $\%$ ) and solubility of calcium oxide.

\begin{tabular}{ccccccc}
\hline Spot & $\mathbf{C a O}$ & $\mathrm{Al}_{\mathbf{2}} \mathbf{O}_{\mathbf{3}}$ & $\mathrm{SiO}_{\mathbf{2}}$ & $\mathbf{M g O}$ & $\begin{array}{c}\text { Solubility of } \\
\text { Calcium Oxide (\%) }\end{array}$ & $\mathbf{R}$ \\
\hline $\mathrm{A}$ & 52.8 & 36.48 & 6.72 & 4 & 52.8 & 7.86 \\
$\mathrm{~B}$ & 40.32 & 48.96 & 6.72 & 4 & 40.32 & 6 \\
$\mathrm{C}$ & 26.88 & 62.4 & 6.72 & 4 & 26.88 & 4 \\
\hline
\end{tabular}

Figure 6 presents the $\mathrm{CaO}-\mathrm{Al}_{2} \mathrm{O}_{3}$ binary phase diagram, which shows that with the increase in calcium oxide, calcium oxide and aluminum oxide generated different inclusions at different temperatures. The ratio of calcium oxide to aluminum oxide was an 
important factor affecting nozzle clogging. The three component points of the optimized slag system are shown in Figure 6. Point A, in the above analysis, had the highest solubility of calcium oxide, and the highest basicity. In the liquid phase inclusion area, point A was the best point in the elliptical optimization area; point $\mathrm{A}$ is in the liquid phase region and is closest to the original slag composition, and the small area centered on point A can be used as the fluctuation range of the optimized slag system.

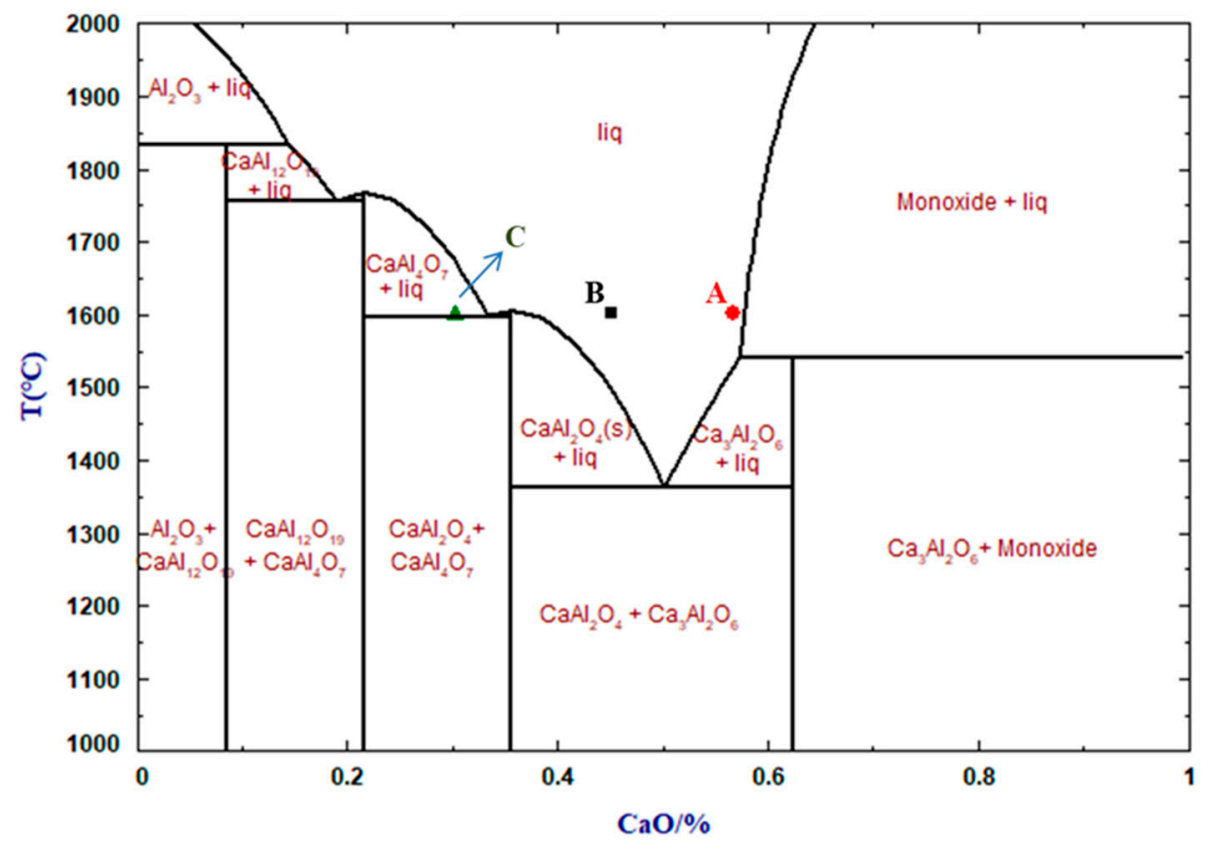

Figure 6. $\mathrm{CaO}-\mathrm{Al}_{2} \mathrm{O}_{3}$ binary phase diagram.

In summary, point A represented the best point of the slag system optimization, and the small area centered on point $\mathrm{A}$ can be used as the optimization target area for industrial tests. Namely, the mass percentage of the optimized slag system was $\mathrm{CaO}: 55-60 \% ; \mathrm{Al}_{2} \mathrm{O}_{3}$ : $20-35 \%$; $\mathrm{SiO}_{2}$ : 3-7\%; $\mathrm{MgO}: 4-8 \% ;(\mathrm{MnO}+\mathrm{FeO})<1 \%$, and the basicity was controlled in the range of $7-11$.

\subsection{Industrial Test}

Through the control of the production process, the refining slag system was in the target optimization area, and the effect of the optimization plan on the removal of Ds inclusions in 10B21 steel was tested. In order to ensure that the optimized slag system in the industrial test would fall into the target area, two random furnaces out of 18 heats were sampled, and the composition was monitored and analyzed from the slag adjustment to the final slag refining. Table 6 shows the composition of the optimized refined slag. The optimized refining slag systems were all within the target optimization range, and the composition changes were stable for each furnace step.

Table 6. Changes in the composition of optimized refined slag series (wt\%).

\begin{tabular}{ccccccc}
\hline Heat & Station & $\mathbf{C a O}$ & $\mathbf{A l}_{\mathbf{2}} \mathbf{O}_{\mathbf{3}}$ & $\mathbf{M g O}$ & $\mathbf{S i O}_{\mathbf{2}}$ & $\mathbf{R}$ \\
\hline \multirow{2}{*}{7} & After slag adjustment & 52.9819 & 25.3667 & 5.2838 & 4.9529 & 10.7 \\
& Final slag & 52.1141 & 24.9165 & 5.489 & 6.4948 & 8 \\
\hline \multirow{2}{*}{9} & After slag adjustment & 55.6516 & 23.1739 & 5.941 & 6.2852 & 8.9 \\
& Final slag & 55.0893 & 23.0281 & 6.1824 & 6.1139 & 9 \\
\hline
\end{tabular}

In order to verify the effect of the optimized slag system on the removal of Ds inclusions in 10B21 steel, the classification results of inclusions before and after optimiza- 
tion were compared. The grading method was based on the Chinese standard SteelDetermination of content of nonmetallic inclusions-Micrographic method using standard diagrams (standard number GB/T 10561-2005). The rating limits of various inclusions are shown in Table 7, and the criteria for defining the thickness of inclusions are shown in Table 8; for more details, please refer to the full text of GB/T 10561-2005. The results in Table 9 show that after optimization, Ds inclusions did not exceed level 0.5, and even most heats no longer appeared as Ds inclusions. Before optimization, Ds inclusions were at least level 1, and some heats even reached level 1.5. Obviously, the inclusion level after the optimization of the slag system was significantly better than that before the optimization of the slag system, indicating that the optimization of the slag system is effective in controlling the Ds inclusions in 10B21.

Table 7. The rating limits of various inclusions.

\begin{tabular}{|c|c|c|c|c|c|}
\hline \multirow[b]{2}{*}{ Rating Chart Level } & \multicolumn{5}{|c|}{ Inclusion Type } \\
\hline & $\begin{array}{c}\text { A } \\
\text { Length }(\mu \mathrm{m})\end{array}$ & $\begin{array}{c}\text { B } \\
\text { Length }(\mu \mathrm{m})\end{array}$ & $\begin{array}{c}C \\
\text { Length }(\mu \mathrm{m})\end{array}$ & $\begin{array}{c}\text { D } \\
\text { Number }\end{array}$ & $\begin{array}{c}\text { Ds } \\
\text { Length }(\mu \mathrm{m})\end{array}$ \\
\hline 0.5 & 37 & 17 & 18 & 1 & 13 \\
\hline 1 & 127 & 77 & 76 & 4 & 19 \\
\hline 1.5 & 261 & 184 & 176 & 9 & 27 \\
\hline 2 & 436 & 343 & 320 & 16 & 38 \\
\hline 2.5 & 649 & 555 & 510 & 25 & 53 \\
\hline 3 & 898 & 822 & 746 & 36 & 76 \\
\hline
\end{tabular}

Table 8. Criteria for determining the thickness of inclusions.

\begin{tabular}{ccccc}
\hline \multirow{2}{*}{ Inclusion Type } & \multicolumn{2}{c}{ Fine } & \multicolumn{2}{c}{ Coarse } \\
\cline { 2 - 5 } & $\begin{array}{c}\text { Minimum Width } \\
(\mu \mathrm{m})\end{array}$ & $\begin{array}{c}\text { Maximum Width } \\
(\mu \mathrm{m})\end{array}$ & $\begin{array}{c}\text { Minimum Width } \\
(\mu \mathrm{m})\end{array}$ & $\begin{array}{c}\text { Maximum Width } \\
(\mu \mathrm{m})\end{array}$ \\
\hline $\mathrm{A}$ & 2 & 4 & $>4$ & 12 \\
$\mathrm{~B}$ & 2 & 9 & $>9$ & 15 \\
$\mathrm{C}$ & 2 & 5 & $>5$ & 12 \\
$\mathrm{D}$ & 3 & 8 & $>8$ & 13 \\
\hline
\end{tabular}

Table 9. Comparison of inclusion rating results before and after optimization.

\begin{tabular}{cccccccccc}
\hline Inclusion Level & Afine & Acoarse & Bfine & Bcoarse & Cfine & Ccoarse & Dfine & Dcoarse & Ds \\
\hline & 0.5 & 0 & 0 & 0 & 0 & 0 & 0.5 & 0.5 & 1.0 \\
Preoptimization & 0.5 & 0 & 1.0 & 1.0 & 0 & 0 & 0.5 & 0.5 & 1.0 \\
level & 0.5 & 0 & 0 & 0 & 0 & 0 & 0.5 & 0.5 & 1.0 \\
& 0.5 & 0 & 0.5 & 0 & 0 & 0 & 0.5 & 0.5 & 1.0 \\
& 0.5 & 0 & 0 & 0 & 0 & 0 & 0.5 & 0.5 & 1.5 \\
\hline \multirow{3}{*}{ Optimized level } & 0.5 & 0 & 0 & 0 & 0 & 0 & 0.5 & 0 & 0.5 \\
& 0.5 & 0 & 0 & 0 & 0 & 0 & 0.5 & 0.5 & 0.5 \\
& 0.5 & 0 & 0.5 & 0 & 0 & 0 & 0.5 & 0.5 & 0 \\
& 0.5 & 0 & 0 & 0 & 0 & 0 & 0.5 & 0.5 & 0 \\
\end{tabular}

Through theoretical calculations and industrial verification methods, the use of such slag system optimization methods can provide ideas for solving other grades of steelrelated problems. 


\section{Conclusions}

1. The composition of Ds inclusions that affect the quality of 10B21 steel is mainly $\mathrm{CaO}-\mathrm{Al}_{2} \mathrm{O}_{3}-\mathrm{MgO}-\mathrm{CaS}-\mathrm{TiN}$, which exists in the form of calcium-magnesium aluminate coated with titanium nitride and calcium sulfide;

2. Ds inclusions are generated during the refining process, and the main reason for their generation is the ineffective refining slag system. In the original refining slag system, calcium oxide was in a supersaturated state and had poor fluidity and low capability to absorb inclusions. The calcium treatment and soft blowing in the refining process aggravated Ds inclusions and resulted in their excessive proportions;

3. Proposed optimization suggestions for refining slag system and conducting industrial tests are as follows: the mass percentage of the optimized slag system is $\mathrm{CaO}$ : $55-60 \% ; \mathrm{Al}_{2} \mathrm{O}_{3}: 20-35 \% ; \mathrm{SiO}_{2}: 3-7 \% ; \mathrm{MgO}: 4-8 \% ;(\mathrm{MnO}+\mathrm{FeO})<1 \%$, and the basicity is controlled between 7 and 11 . The optimized refining slag system can significantly improve the ability of the system to absorb inclusions, especially for Ds inclusions, which improves the qualification rate of the resulting produced 10B21 steel.

Author Contributions: Conceptualization, W.L. and Y.C.; data curation, Z.S.; formal analysis, Z.S.; funding acquisition, S.Y.; investigation, W.L. and X.Z.; methodology, W.L.; project administration, Y.C.; resources, Y.L.; software, Y.L.; supervision, S.Y. and J.L.; validation, Y.C.; visualization, W.L.; writing-original draft, Z.S.; writing-review and editing, Z.S. and Y.L. All authors have read and agreed to the published version of the manuscript.

Funding: National Natural Science Foundation of China: 51822401 and 51734003; China Postdoctoral Science Foundation: 2020M680010; Fundamental Research Funds for Central Universities: FRF-TP18-009C1.

Data Availability Statement: Not applicable.

Acknowledgments: The authors would like to thank Wuhu Xinxing Casting Pipe Co., Ltd. for its strong support for sampling work.

Conflicts of Interest: The authors declare no conflict of interest.

\section{References}

1. Chen, K.J.; Hung, F.Y.; Lui, T.S.; Tseng, C.H. Decrease in Hydrogen Embrittlement Susceptibility of $10 \mathrm{~B} 21$ Screws by Bake Aging. Metals 2016, 6, 7. [CrossRef]

2. Chen, K.J.; Hung, F.Y.; Lui, T.S.; Tseng, C.H. Effects of Tempered Microstructure and Hydrogen Concentration on HydrogenInduced Embrittlement Susceptibility of 10B21 Screws at Low Temperature. Mater. Trans. 2018, 59, 1124-1129. [CrossRef]

3. Yang, C.C.; Wang, S.T. Improvement of Mechanical Properties of Spheroidized 10B21 Steel Coil Using Taguchi Method of Robust Design. Sens. Mater. 2018, 30, 503-514.

4. Zeng, D.F.; Lu, L.T.; Zhang, J.W.; Jin, X.S.; Zhu, M.H. Effect of micro-inclusions on subsurface-initiated rolling contact fatigue of a railway wheel. Proc. Inst. Mech. Eng. Part F-J. Rail Rapid Transit 2016, 230, 544-553. [CrossRef]

5. Gubeljak, N.; Predan, J.; Sencic, B.; Chapetti, M.D. Effect of Residual Stresses and Inclusion Size on Fatigue Resistance of Parabolic Steel Springs. Mater. Test. 2014, 56, 312-317. [CrossRef]

6. Ma, M.Y.; Zhang, J.Y.; Yi, D.Q.; Wang, B. Investigation of high-cycle fatigue and fatigue crack propagation characteristic in 5083-O aluminum alloy. Int. J. Fatigue 2019, 126, 357-368. [CrossRef]

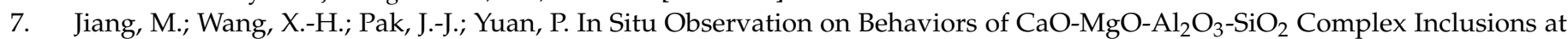
Solid-Liquid Interface of Low-Oxygen Special Steel. Metall. Mater. Trans. B-Process Metall. Mater. Process. Sci. 2014, 45, 1656-1665. [CrossRef]

8. Wang, L.; Xin, J.; Cheng, L.; Zhao, K.; Sun, B.; Li, J.; Wang, X.; Cui, Z. Influence of inclusions on initiation of pitting corrosion and stress corrosion cracking of X70 steel in near-neutral pH environment. Corros. Sci. 2019, 147, 108-127. [CrossRef]

9. Wu, H.; Li, Q.; Wei, C.; Wang, Z. Study on the behaviour of DS-Class inclusions in advanced bearing steel. Metall. Res. Technol. 2019, 116, 223. [CrossRef]

10. Min, Y.; Jiang, M.-f. Exergy Analysis and Optimization of Ladle Furnace Refining Process. J. Iron Steel Res. Int. 2010, 17, 24-28. [CrossRef]

11. Jang, H.-S.; Ryu, J.W.; Sohn, I. FeMn Metal Droplet Behavior in the MnO-SiO2-CaO Slag System. Metall. Mater. Trans. B-Process Metall. Mater. Process. Sci. 2015, 46, 606-614. [CrossRef]

12. Tang, H.-Y.; Wang, Y.; Wu, G.-H.; Lan, P.; Zhang, J.-Q. Inclusion evolution in 50CrVA spring steel by optimization of refining slag. J. Iron Steel Res. Int. 2017, 24, 879-887. [CrossRef] 
13. Ge, Y.; Zhao, S.; Ma, L.; Yan, T.; Li, Z.; Yang, B. Inclusions Control and Refining Slag Optimization for Fork Flat Steel. Metals 2019, 9, 253. [CrossRef]

14. Chen, G.-J.; He, S.-P.; Guo, Y.-T.; Shen, B.-Y.; Zhao, S.; Wang, Q. Optimization of Calcium Addition to High-strength Low-alloy Steels. J. Iron Steel Res. Int. 2015, 22, 590-597. [CrossRef]

15. Tabatabaei, Y.; Coley, K.S.; Irons, G.A.; Sun, S. Tracking Inclusions during Ladle Refining Using a Kinetic Model for the Compositions of Metal, Slag, and Inclusions. Steel Res. Int. 2019, 90, 1900195. [CrossRef]

16. Sui, Y.; Yue, C.; Peng, B.; Wang, C.; Guo, M.; Zhang, M.; Seetharaman, S. Optimization of Slag Chemistry Toward Inclusion Control for 28CrMo47 Drill Pipe Steel Based on Viscosity and Equilibration Studies. Steel Res. Int. 2016, 87, 752-760. [CrossRef]

17. Zhao, S.; He, S.P.; Guo, Y.T.; Chen, G.J.; Lv, J.C. Effect on cleanliness of molten steel with different refining slag systems for low alloy ship plate. Ironmak. Steelmak. 2016, 43, 790-798. [CrossRef]

18. Yang, L.-L. Analysis of the refining effect of pipeline steel LF. Steelmaking 2012, 28, 37-39+59.

19. Gu, C.; Bao, Y.P.; Lin, L.; Wang, M.; Zhao, L.H.; Wu, Z.X. Study on Adjustment and Optimization of LF Refining Slag of Spring Steel 55SiCrA. In Proceedings of the 3rd Pan American Materials Congress; FEB 26-MAR 02; Springer: Cham, Swizerland, 2017; pp. 783-789.

20. Zhao, S.; Wang, Q.; Chen, G.J.; He, S.P.; Peng, M.M. Optimization on refining slag and tapping deoxidation system for carbon structure steel without calcium treatment. Charact. Miner. Met. Mater. 2014, 2014, 305-312. 